\title{
Experimental Study of the Acid Corrosion Effects on an Intumescent Coating for Steel Elements
}

\author{
Ji Wang, ${ }^{\dagger}+$ Wen-hua Song, ${ }^{* \dagger}$ Miao Zhang, ${ }^{\dagger}$ and Zhen Chen ${ }^{\S}$ \\ ${ }^{\dagger}$ Environment and Chemistry College, Tianjin Polytechnic University, Tianjin, 300387, China \\ ${ }^{\ddagger}$ Fire Protection Engineering Department, Chinese People’s Armed Police Forces Academy, Langfang, Hebei 065000, China \\ ${ }^{\S}$ Institute of Mechanics, Chinese Academy of Science, Beijing, 100190, China
}

ABSTRACT: Acid corrosion may cause the deterioration of the fire resistance of the intumescent fire retardant coatings. This paper reported the results of an experimental study of degradation in fire protection performance of intumescent coating for steel elements after different times of immersion in the hydrochloric acid solution. The morphology, the equivalent thermal resistance, and the changes of the elements and groups contained on the surface of the coatings were investigated. The corrosion mechanism was as follows: when the coating was immersed in the acid solution, the ammonium polyphosphate (APP), pentaerythritol (PER), and melamine (MEL) underwent the process of acid catalyzed hydrolysis, dissolution, and chemical reaction, which led the change of the content ratio of the compositions and caused the deterioration of the coating fire resistance. A prediction method of the remaining fire resistance property for the acid corrosion coatings was proposed, by comprehensively considering the physical and chemical characteristic changing trends of the corroded coating.

\section{INTRODUCTION}

Steel elements are widely used in the industrial and civil buildings due to their unique advantages, such as high strength, good plasticity and toughness characteristics, lightweight, simple manufacturing process, short construction time, and good economic benefit. However, the high temperature performance of the steel elements is not ably poor. The strength and the elastic modulus decrease rapidly at $400{ }^{\circ} \mathrm{C}$, and the yield strength is less than $30 \%$ of the strength at room temperature. In addition, because of the low thermal conductivity, the heating speed of the steel elements is notably fast under the conditions of fire. All of the above causes lead to only approximately $15 \mathrm{~min}$ of fire resistance of the steel elements if they are not protected by protection measures.

To enhance the fire resistance of the steel element buildings and guarantee the safety of personnel, property, and buildings, fire protection measures are required. Using a certain thickness of fire retardant coating is one of the commonly used methods, and intumescent coating is preferred due to the use of only a thin layer and its good decoration characteristics. Whereas the occurrence of fire is random, it may occur after one year of the application of the coating, or even ten years and longer, and whether the performance of the fire retardant coating remains as the original coating must be considered.

There are many reported research studies in the open literature concerning the durability of coatings. ${ }^{1-6}$ However, the studies on the long-term fireproofing of fire retardant coatings are relatively few. Sakumoto et al. conducted some accelerated tests and small-scale heat tests, and on the basis of their results, they proposed a new testing method for evaluating the durability of intumescent coatings by considering the hightemperature and high-humidity weather conditions in Japan. ${ }^{7}$ In the work of Roberts et al., Shell UK performed a long-term passive fire protection weathering program at a maritime test site using furnace tests to assess the fire performance of the materials. ${ }^{8}$ Ling-ling Wang reported the results of an experimental study of degradation in the fire protection performance of two types of intumescent coatings after different cycles of accelerated hydrothermal aging tests and proposed an aging mechanism according to the experiment results. ${ }^{9}$ Jimenez et al. studied the fire performance deterioration of an intumescent coating (which contains epoxy resin, ammonium polyphosphate, melamine, and titanium dioxide) in three different accelerated aging conditions ( $80 \%$ moisture atmosphere at $70{ }^{\circ} \mathrm{C}$ for 2 months and a static immersion bath with and without $\mathrm{NaCl}(5 \mathrm{~g} / \mathrm{L})$ at $20{ }^{\circ} \mathrm{C}$ for 1 month $) .{ }^{10}$

With the development of industrialization of human society, an acidic atmospheric environment has become one of the problems of greatest concern. Acid atmospheric precipitation is formed when specific pollutants combine with water or dust particles in the atmosphere. By far, the largest contribution to this problem arises from sulfur dioxide $\left(\mathrm{SO}_{2}\right)$, a byproduct of fossil fuel combustion. Sulfur dioxide becomes oxidized to $\mathrm{H}_{2} \mathrm{SO}_{4}$, which accounts for $62-79 \%$ of the acidity of rain. Most of the remaining acid is from the nitrogen oxides $\left(\mathrm{NO}_{x}\right)$, produced mainly in automobile exhaust gas, that are oxidized to $\mathrm{HNO}_{3}(15-32 \%)$. In addition to these two main species, $\mathrm{HCl}$ $(2-16 \%)$, produced by burning coal, is also found in the atmosphere. ${ }^{11}$ In the actual projects, the main acid media that corrode the fire retardant coatings for outdoor use are acid rain, dew, fog, and dust. In particular, for petrochemical enterprises, the acid corrosive effects are much more significant due to the emission of a large amount of acidic gases. For example, in the summer of Jacksonville, a port city in the U.S., the $\mathrm{pH}$ of the rain was in the range of 3.5 to 5.5. ${ }^{12}$ Therefore, in this paper,

Received: May 7, 2014

Revised: June 10, 2014

Accepted: June 19, 2014 

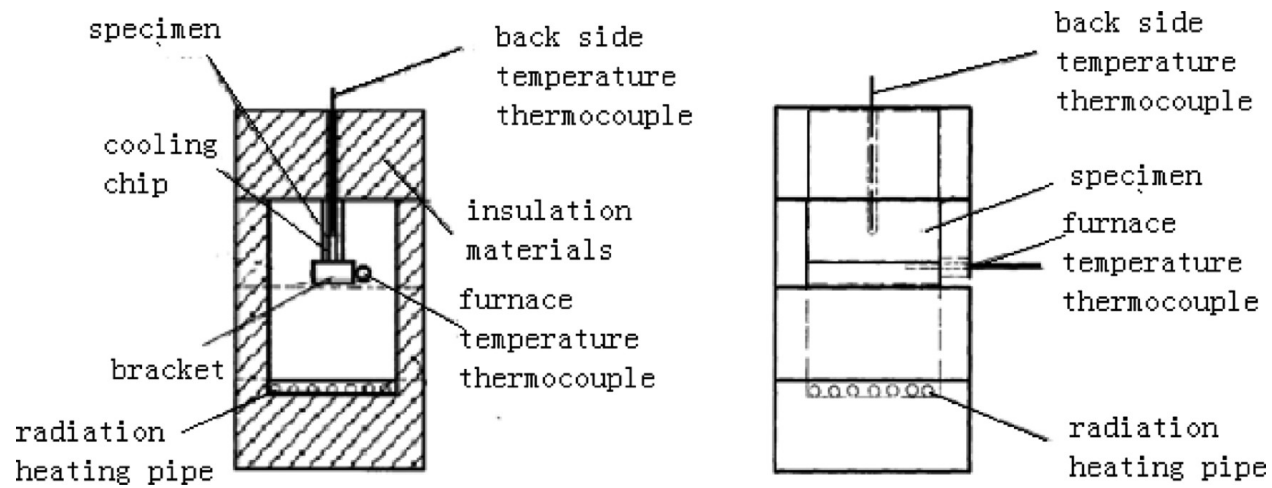

Figure 1. Sections of the fire retardant coating testing furnace.

a study of the acid durability of the intumescent fire retardant coating is presented, and a method for predicting the residual fire resistance is proposed. The results of this paper serve as a reference for the correct use of the fire coating in a heavily corrosive environment.

\section{EXPERIMENTAL SECTION}

2.1. Specimen Preparation. The fire retardant coating used in this study was a solvent intumescent coating for outdoor steel structure. The base material of the coating was acrylic resin. The PVC (pigment volume concentration) of the coating is an important parameter for the dry layer since it is directly proportional to film permeability and has an influence on decorative appearance and on the degree of intumescence. The PVC of the coating was about $65 \%$. The specimen substrate was a Q235 steel plate of $80 \mathrm{~mm} \times 40 \mathrm{~mm} \times 1.2 \mathrm{~mm}$. Before brushing the coating, the steel substrates were cleaned thoroughly. In the real building engineering, the protective system for steel substrate is a multilayer, which includes the top coating, the fire retardant coating, and the primer. The primer not only can play the role of antirust and corrosion but also can increase the cohesion between the substrate and the coating layer. The zinc rich primer based on epoxy resin was brushed prior to the fire retardant coating, and the thickness of the primer was $63.8 \mu \mathrm{m}$. The intervals between the coating layer and the whole thickness were set according to the instructions of the product. The fire retardant coatings were brushed five times, and the thickness of the dry layer was $0.7 \mathrm{~mm}$. Generally, the top coatings applied on fire-retardant paints prevent or limit the intumescence since they are formulated with low PVC values to reach reduced film permeability. To investigate the acid corrosion effects directly on the fire retardant coating layer, the top coating was not used in this study.

The specimens were held for 30 days in the condition of $20 \pm 5{ }^{\circ} \mathrm{C}$ and $\mathrm{RH} 60 \% \pm 10 \%$ after the coating was applied. Next, the edge and back sides of the specimens were sealed by a mixture of resin and paraffin (1:1 in weight).Under the same conditions mentioned above, the sealed specimens were held for $24 \mathrm{~h}$. Subsequently, two-thirds of the specimens were immersed vertically in a hydrochloric acid solution (3\% in weight $)^{13}$ for $8,16,24$, and $72 \mathrm{~h}$. All the specimens were dried at the laboratory conditions before testing.

2.2. Testing Equipment and Conditions. To investigate the acid corrosion mechanism of the intumescent fire retardant coating, the fire resistance, the morphologies of the coating and char layer, the composition of the elements, and the thermal stability of the different corrosion time specimens were tested.
The fire resistance of the intumescent coatings of the acid treated samples was tested by a small-scale fireproof testing furnace. ${ }^{14}$ Figure 1 shows the sections of the furnace used. During testing, the uncoated sides of two specimens were attached at the lower end of the respective sides of a cooling chip, which was made of steel or heat-resistant alloy. Wire was used to combine the cooling chip and the two samples covering the sides of the cooling chip together. The cooling chip and the two samples were placed onto the bracket in the furnace vertically. One thermocouple was placed in the groove of the cooling chip to measure the back-side temperature of the specimens, and another thermocouple was placed in the furnace to monitor the temperature of the furnace. The timetemperature curve in the furnace is in accordance with the ISO 834 standard curve. The time when the back side temperature of the samples reaches $538{ }^{\circ} \mathrm{C}$ is defined as the fireresistance time. Figure 2 shows the time-temperature curve comparison between the furnace results and the ISO 834 standard.

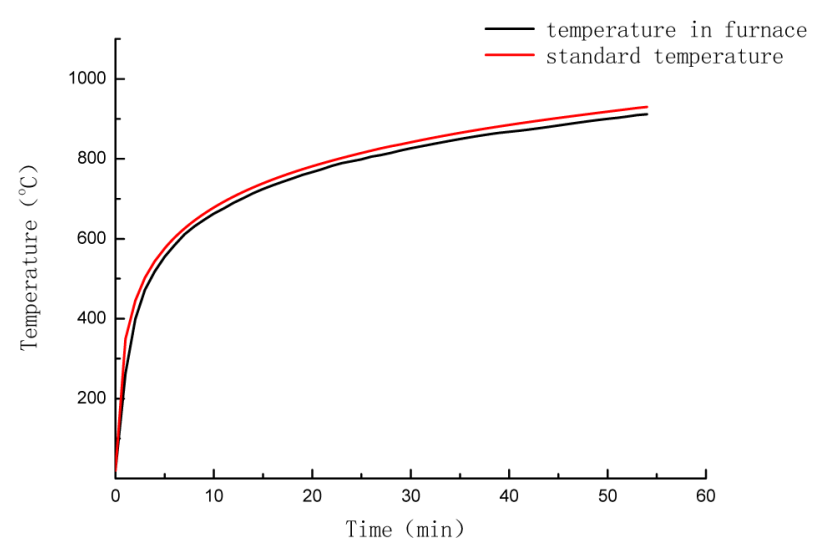

Figure 2. Time-temperature comparison diagram between the furnace and the ISO 834 standard.

After emission in the acid solution for some hours, the apparent morphology of the specimens differs from that of the original ones. To observe the morphology clearly, a scanning electron microscope (SEM) was used at a magnification of $500 \times$. The fire performance of the intumescent coating is not only determined by the composition, thickness, and strength of the foamed char but also the morphology of the char. The alteration of the char morphology could be one of the main causes leading to the deterioration of the coating fire resistance. In this study, the morphology of the foamed char layer was investigated using the stereo microscope at a magnification of 
$100 \times$. The elements and groups contained on the surface of the samples were measured using X-ray photoelectron spectroscopy (XPS) and Fourier transform infrared (FT-IR) spectroscopy to understand the changes of the molecular structure in the process of corrosion.

\section{EXPERIMENTAL RESULTS}

3.1. The Surface Morphology of the Coating after Corrosion. Compared with the original coating sample, the surface of the specimens following acid corrosion appeared rougher and thinner. Measuring the thicknesses of the two points that were near the dent, the difference was the thinning of the coating. Five pairs of points were measured, and the average of the differences was used as the final thickness measured. Table 1 shows the thickness of the coatings after

Table 1. Thickness of the Coating after Different Periods of Acid Corrosion

\begin{tabular}{lrrrr} 
corrosion time $(\mathrm{h})$ & \multicolumn{1}{c}{8} & \multicolumn{1}{c}{16} & \multicolumn{1}{c}{24} & \multicolumn{1}{c}{72} \\
thinning thickness of the coating $(\mu \mathrm{m})$ & 63.3 & 79.6 & 103.8 & 195.1 \\
loss rate of the coating $(\mu \mathrm{m} / \mathrm{h})$ & 7.9 & 5.0 & 4.3 & 2.7
\end{tabular}

different periods of acid corrosion. The loss rate of the coating is the amount of thinning of the coating per hour.

To investigate the changes of the surface morphology, the coating surfaces after different acid treatment times were observed using the SEM. Figure 3 shows the surface morphology at a magnification of 500x. The data shown in Figure 3 indicate that the surface of the untreated coating is relatively smoother compared to the acid treated surfaces. The base resin covered and bonded the surface of the pigments and fillers continuously in the untreated coating. However, the corroded specimen surface was no longer flat, and some particles appeared. After $24 \mathrm{~h}$ of corrosion, the particles became smaller and were fewer in number. In addition, some cracks and broken holes could be observed in the corroded samples surface.

Analysis of the data suggested that the particles in the coating surface were the functional pigments of the retardant system, mainly, ammonium polyphosphate (APP), melamine (MEL), and pentaerythritol (PER). The APP is hydrolytic and produces ammonium ions $\left(\mathrm{NH}_{4}^{+}\right)$and pyrophosphate in a corrosive environment. ${ }^{15}$ The process of the hydrolysis would be catalyzed by the action of the $\mathrm{NH}_{4}{ }^{+}$and $\mathrm{Cl}^{-}$in the hydrochloric acid solution, leading to the production of ammonium chloride. $^{25}$ The process of hydrochloric acid penetrating into the coating and the process of ammonium polyphosphate diffusing to the surface occurred simultaneously. With increasing corrosion time, the consumption of the ammonium polyphosphate increased gradually, while the diffusion speed decreased. As a result, in the final period of long time corrosion, the action was mainly between the hydrochloric acid and the APP in the coating surface, which caused the particles of APP to become smaller.

In the meantime, ammelid, ammeline, and cyanuric acids are produced due to the action of MEL and hydrochloric acid. All the new products are water-soluble, which reduced the content of the MEL in the coating. PER also exhibits a degree of watersolubility, so as with the other two pigments, the diffusion to

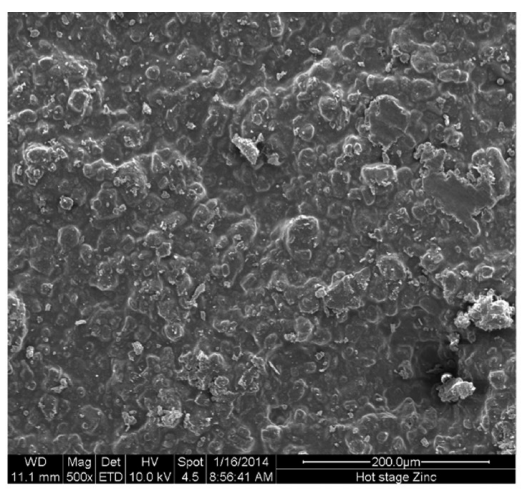

a. Untreated coating surface

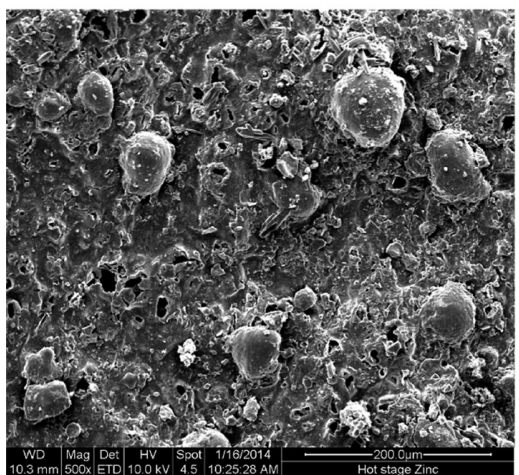

c. Coating surface after $16 \mathrm{~h}$ corrosion

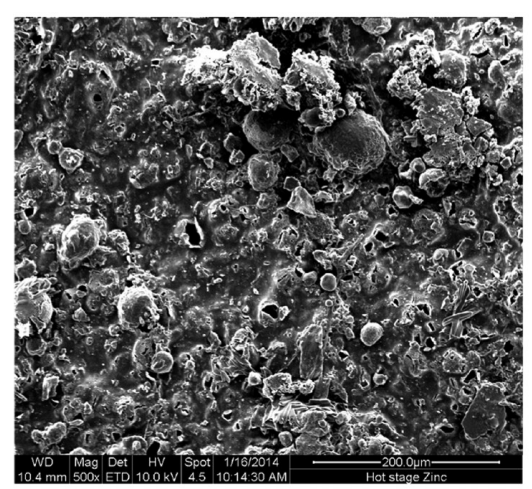

b. Coating surface after $8 \mathrm{~h}$ corrosion

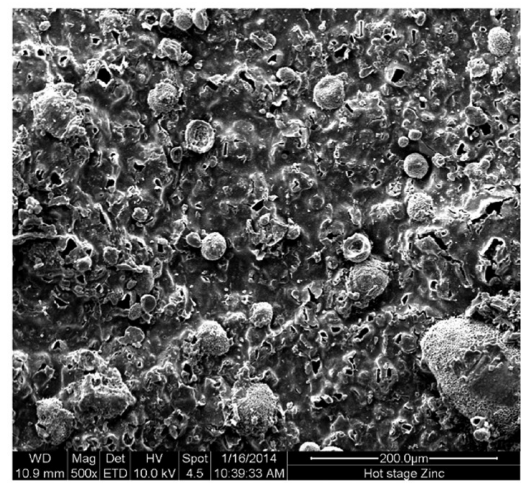

d. Coating surface after $24 \mathrm{~h}$ corrosion

Figure 3. Surface morphology after different times of corrosion. 
the surface and the consumption occur during the immersion process. In the immersion process, the hydrochloric acid and water would penetrate into the coating through the gap between the coating compositions; in addition, the coating pigments diffused to the surface, so that the coating swelled and became soft and the volume became larger. After the specimens were removed from the solution, during the period of the drying of the specimens, the absorbed water evaporates and the coating layer shrinks and becomes hard, eventually forming cracks. Broken holes would form after the drying process if spherical bubbles were produced during the coating swelling and softening. The coating surface is no longer continuous and integrated due to the presence of the cracks and holes, which affect the mechanical properties of the coating.

3.2. The Fire Resistance of the Coating after Corrosion. 3.2.1. The Fire Resistance Time and the Thickness of the Char Layer. When the specimens met the prescribed corrosion time, they were moved from the hydrochloric acid solution and then dried under laboratory conditions. Before conducting the fire resistance test, the mixture layer of resin and paraffin was removed. Figure 4 shows the back side temperature of the samples with testing time. For different corrosion time samples, the trends of the temperature rising was found to be similar in the early $400 \mathrm{~s}$, but the behaviors became quite different in the later stage.

The fire resistance performance of the intumescent coating is affected by the thickness and the morphology of the char layer.

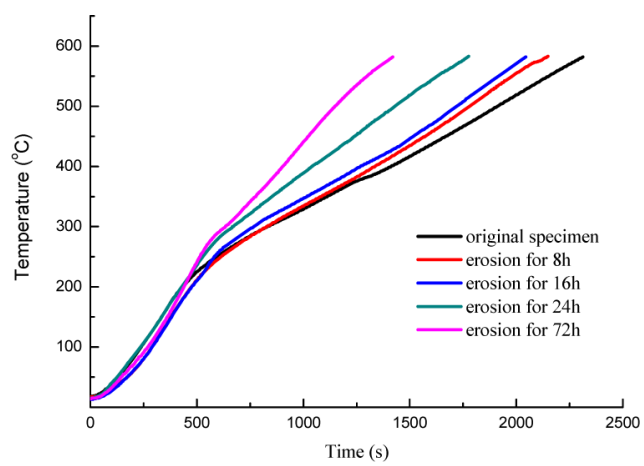

Figure 4. Back side temperature of specimens vs time.

The thicker, more compact, and stronger the char layer, the longer is the fire resistance time. As a result, to investigate the alteration of the fire property of the coating due to acid corrosion, in addition to testing the fire resistance time, the thickness and the morphology of the char layer must be measured. Table 2 presents the fire resistance time and char thickness of the coating after different times of acid corrosion.

The aging rate in Table 2 is the rate of fire resistance time shortening of the coating specimens after acid corrosion. That is

$$
\text { aging rate }=\frac{\text { fire resistance time of the untreated sample }- \text { fire resistance time of the corroded sample }}{\text { fire resistance time of the untreated sample }}
$$

This parameter reflects the fire resistance time variation amplitude of the samples after acid corrosion. From Table 2, along with the immersion time in hydrochloric acid solution prolonged, the fire resistance times of the coatings are found to gradually shorten and the aging rates are found to increase. The fire resistance time of $39 \mathrm{ft} 25 \mathrm{in}$. of the original sample was shortened to $24 \mathrm{ft} 06 \mathrm{in}$. for the sample after corrosion for $72 \mathrm{~h}$, with an aging rate of $38.4 \%$. Because, in this study, the samples were not immersed in the acid solution completely, only twothirds of the length of each sample was corroded; therefore, the fire resistance times listed in the table are longer than the times for samples whose lengths are entirely corroded and the aging times are smaller.

The expansion rate can be interpreted as the following formula.

$$
\text { expansion rate }=\frac{\text { thickness of the char layer }- \text { initial thickness of the coating }}{\text { initial thickness of the coating }}
$$

In the same initial thickness of the coating, the higher the expansion rate, the thicker is the char layer and the slower is the heating rate of the protected substrate; correspondingly, the fire resistance performance is improved. The initial thickness of the untreated coating is the coating thickness before corrosion, and the initial thickness of the corroded coating is the reduced thickness of the sample after corrosion. The expansion rate of the original specimen is about 40; however, it may be much higher for different brands of coating with different formulas.

3.2.2. The Morphology of the Char Layer. The char layer of each of the corroded specimens for different times of corrosion was observed after the fire resistance time test; besides the thickness, the morphology was found to be dramatically varied. Figure 5a shows the char layer section of the original coating. The char layer was observed to be spongy and expanded evenly and compactly, without large pores or cracks, and the structure of the char layer surface was the same as that of the internal structure. Figure $5 \mathrm{~b}$ shows the char layer of the specimen corrosion for $8 \mathrm{~h}$. The char layer of the untreated part was similar to that of the original one, and the surface was spongy and soft. However, on the surface of the char layer of the corroded part, there was a shell that was harder than the untreated char. In addition, the shell surface appeared to be relatively rough and uneven, and there were many small expansion char bubbles.

Figure 6a shows the surface of the char layer of the sample exposed to $16 \mathrm{~h}$ of acid corrosion. The surface appears similar to the char layer of the sample exposed to $8 \mathrm{~h}$ of acid corrosion. A hard shell also appeared, but the roughness was less than that in the $8 \mathrm{~h}$ acid corrosion case, and there were cracks in the surface shell. After removing the hard shell, large cracks and holes could be observed in the internal char layer, as shown in Figure $6 \mathrm{~b}$. Similar to the char layers of the samples under acid corrosion for 8 and $16 \mathrm{~h}$, there was hard shell on the char layer surface of the sample under acid corrosion for $24 \mathrm{~h}$. The shell 
Table 2. Fire Resistance Time and Char Thickness of the Coating after Different Times of Acid Corrosion

\begin{tabular}{|c|c|c|c|c|c|c|}
\hline \multirow[b]{2}{*}{ corrosion time $(\mathrm{h})$} & \multirow[b]{2}{*}{ fire resistance time } & \multirow[b]{2}{*}{ aging rate $(\%)$} & \multicolumn{2}{|c|}{ untreated layer } & \multicolumn{2}{|c|}{ corrosion layer } \\
\hline & & & thickness of the char (mm) & expansion rate & thickness of the char $(\mathrm{mm})$ & expansion rate \\
\hline 0 & $39 \mathrm{ft} 25 \mathrm{in}$. & & 29.2 & 39.6 & & \\
\hline 8 & $35 \mathrm{ft} 46$ in. & 9.3 & 27.5 & 37.2 & 23.6 & 31.8 \\
\hline 16 & $33 \mathrm{ft} 27 \mathrm{in}$. & 15.1 & 27.2 & 36.8 & 16.6 & 24.8 \\
\hline 24 & $29 \mathrm{ft} 43 \mathrm{in}$. & 24.6 & 26.8 & 36.2 & 13.6 & 20.9 \\
\hline 72 & $24 \mathrm{ft} 06$ in. & 38.4 & 22.4 & 30.1 & not expansion & \\
\hline
\end{tabular}
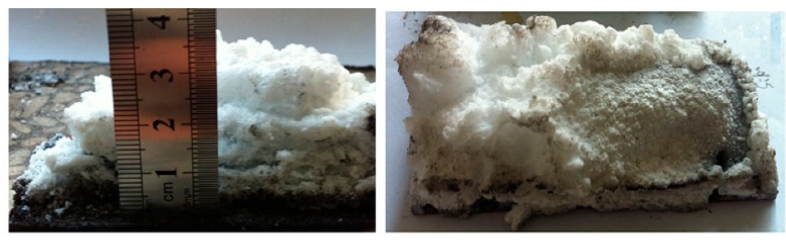

a. The char layer of the original sample b. The char layer of the 8-h corrosion sample

Figure 5. Char layer of the original and $8 \mathrm{~h}$ corrosion samples.

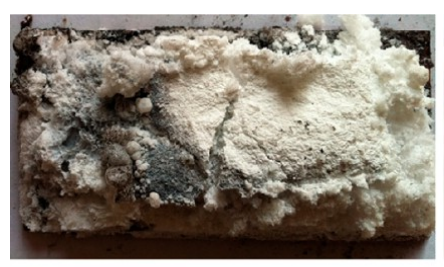

a. The surface of the char layer

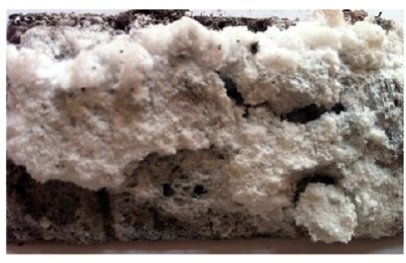

b. The internal part of the char layer
Figure 6. Char layer of the $16 \mathrm{~h}$ corrosion sample.

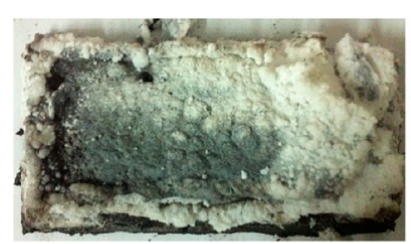

a. The surface of the char layer

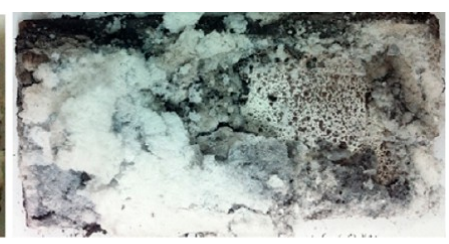

b. The internal part of the char layer
Figure 7. Char layer of the $24 \mathrm{~h}$ corrosion sample.

surface was smooth overall, and a few of the expansion char bubbles could be observed closely next to the untreated part char layer (Figure 7a). After removing the hard shell, the steel substrate could be observed, and most of the corroded part was without char. Figure 8 shows the char layer of the specimen

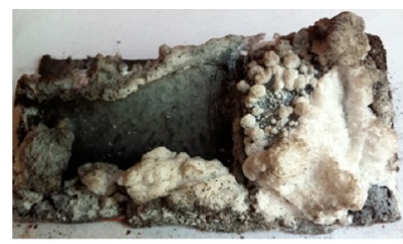

a. The surface of the char layer

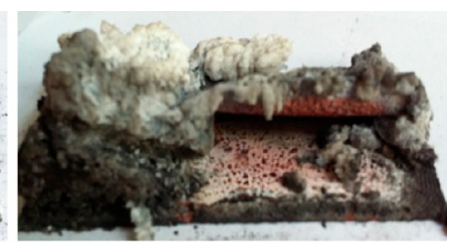

b. The side view of the char
Figure 8. Char layer of the $72 \mathrm{~h}$ corrosion sample.

under acid corrosion for $72 \mathrm{~h}$. Figure $8 \mathrm{a}$ shows that the corrosion part did not expand at all, the surface was smooth, the color of the char layer was dark gray, and no obvious expansion char bubble was found. From the side view, the shell was curling and peeled from the substrate, as shown in Figure $8 b$.
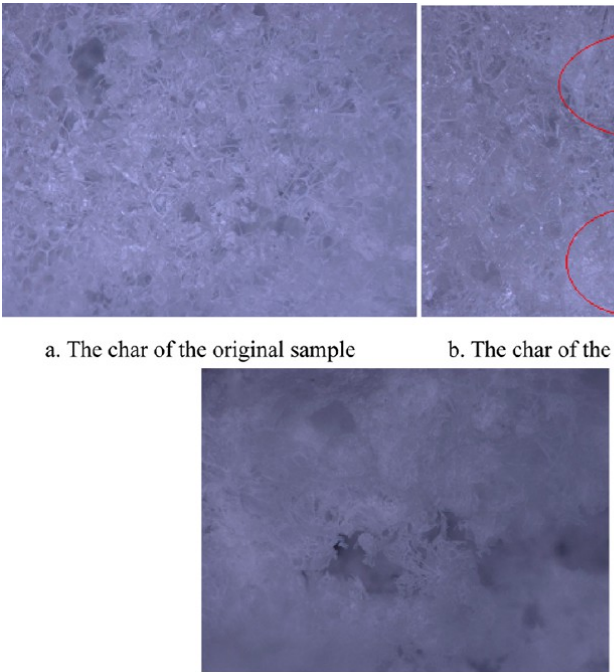

c. The char of the sample for $16 \mathrm{~h}$ corrosion a. The char of the original sample

Figure 9. Longitudinal section morphology of the char.

To understand the details of the char layer, the morphology of the longitudinal section of the char was observed using stereo microscope at $100 \times$ magnification. Figure $9 a-c$ is the char section of the original sample, the corroded sample after $8 \mathrm{~h}$ of corrosion, and the corroded sample after $16 \mathrm{~h}$ of corrosion, respectively. As shown in the figure, the char of the untreated coating appeared spongy and fluffy, the reinforced fibers of the coating were uniformly distributed in the char layer, and the pores were small and relatively consistent in size. Some "cement" parts (the regions in the red circles of Figure 9b) were formed in the char layer of the sample after $8 \mathrm{~h}$ of acid corrosion. The char was not as fluffy as the original one, and the reinforced fiber and the char were bonded together in the "cement" part and could not be distinguished clearly. The pores in the char were large and of nonuniform size. Much more "cement" parts were formed in the char of the $16 \mathrm{~h}$ corrosion sample, and only in the vicinity of the pores can the reinforced fiber be identified. The pores in the char became obviously large and small.

The loss of some active components, such as APP, PER, and MEL, may affect the expansion rate of the coating and lead to the change of the char morphology. In the process of heating, the components of the coating were melting, decomposing, and shrinking, which generated the "cement" parts. Due to the lack of an explosive system in the region of the "cement", there were few pores in it. In addition, besides the contraction of the unexpanded "cements", the changing proportions of the active materials resulted in the phenomenon of the large and uneven process. All of the aspects mentioned above affect the heat insulation effect of the char and cause the fire resistance property to become worse. 
Using the VHX-100 communication software, the magnitude of the pores in the char were measured and calculated. During the measurement, the pores with clear boundaries were selected. In the visual range, the measured pores were numerous and distributed uniformly. For the irregularly shaped pores, the longest distance between two points at the edge of the pore was the pore size. Figure 10 shows the pore

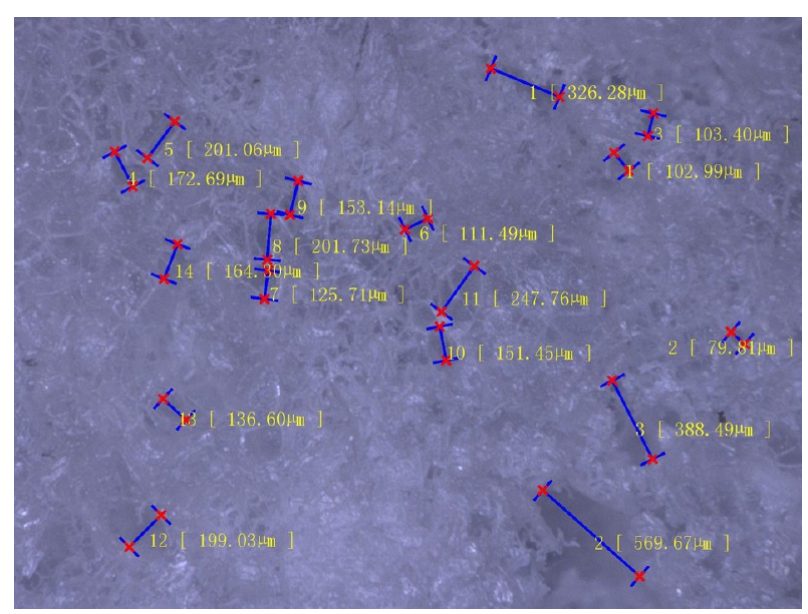

Figure 10. Pore measurement figure of the $8 \mathrm{~h}$ corrosion sample.

measurement results of the $8 \mathrm{~h}$ corrosion sample. Table 3 presents the measured and calculated data regarding the pore size of the samples of different corrosion periods. Because the char layer of the $24 \mathrm{~h}$ corrosion sample was too loose and thin for the observation and the $72 \mathrm{~h}$ corrosion sample was not expanded, the two samples were not considered in this test. As seen in Table 3, with the increasing time of corrosion, the size of the char became larger. In addition, the magnitudes of the pore sizes were more dispersed and uneven, resulting in an increase in the pore range, variance, and standard deviation.

3.2.3. The Thermal Resistance of the Char Layer. In the fire events, the temperature increasing process of the fire coating protected steel structure is directly related to the fire resistance performance of the coating char layer. The smaller the thermal conductivity of the char, the better is the heat insulation, if the other conditions are the same. As a result, the thermal conductivity is commonly used to characterize the heat insulation property of the fire coating in many related studies. By considering the methods and models used to determine the equivalent thermal conductivity of the coating, it is found that there are two main methods: one is using an empirical formula ${ }^{16-21}$ and the other is conducting a numerical calculation based on the principle of the heat conduction. ${ }^{22}$

The heat insulation effect of the fire retardant coating also depends on the thickness of the coating char, especially for the intumescent fire retardant coating. The coating expansion ratio and the char layer thickness directly affect the temperature increase of the protected steel elements. The thermal conductivity itself can not reflect the influence of the char layer thickness. Therefore, the heat insulation property of the coating was characterized by the thermal resistance. ${ }^{23}$

When the heat absorbed by the coating and the temperature difference in the steel element were ignored, the iterative equation for calculating the temperature increase of the element was established on the basis of the lumped heat capacity principle; ${ }^{24}$ it is given by

$$
\Delta T_{\mathrm{s}}=\frac{\lambda_{\mathrm{i}} / d_{\mathrm{i}}}{\rho_{\mathrm{s}} c_{\mathrm{s}}} \frac{A_{i}}{V}\left(T_{\mathrm{g}}-T_{\mathrm{s}}\right) \Delta t
$$

where $d_{\mathrm{i}}$ is the thickness of the insulation, $\mathrm{m} ; \lambda_{\mathrm{i}}$, the thermal conductivity of the insulation, $\mathrm{W} /\left(\mathrm{m} \cdot{ }^{\circ} \mathrm{C}\right) ; A_{\mathrm{i}}$, the appropriate area of the fire insulation material per unit length, $\mathrm{m}^{2} / \mathrm{m} ; V$, the volume of the steel per unit length, $\mathrm{m}^{3} / \mathrm{m} ; \rho_{\mathrm{s}}$, the density of the steel element, $\mathrm{kg} / \mathrm{m}^{3} ; c_{\mathrm{s}}$, the specific heat of the steel element, $\mathrm{J} / \mathrm{kg} \cdot{ }^{\circ} \mathrm{C} ; T_{\mathrm{s}}$, the steel element temperature at $t$ moment, ${ }^{\circ} \mathrm{C} ; \mathrm{T}_{\mathrm{g}}$, the air temperature at $t$ moment, ${ }^{\circ} \mathrm{C} ; \Delta t$, the time increment (generally more than $30 \mathrm{~s}$ ), s; $\Delta T_{\mathrm{s}}$, the temperature rise of the steel element in $\Delta t,{ }^{\circ} \mathrm{C}$.

The equivalent thermal resistance, $R_{\mathrm{i}}\left(\mathrm{K} \cdot \mathrm{m}^{2} / \mathrm{W}\right)$, of the coating can be defined as

$$
R_{\mathrm{i}}=\frac{d_{\mathrm{i}}}{\lambda_{\mathrm{i}}}
$$

Rearranging eqs 1 and 2, we obtain the equation for calculating the equivalent thermal resistance of the coating:

$$
R_{\mathrm{i}}=\frac{\left(T_{\mathrm{g}}-T_{\mathrm{s}}\right)}{\Delta T_{\mathrm{s}} / \Delta t} \frac{1}{\rho_{\mathrm{s}} c_{\mathrm{s}}} \frac{A_{\mathrm{i}}}{V}
$$

Thus, with the steel sample and the environmental temperature changes with time obtained by the heating test and the physical and geometric parameters of the steel sample, the thermal resistance can be calculated by the iterative eq 3 . Figure 11 shows the equivalent thermal resistance of the

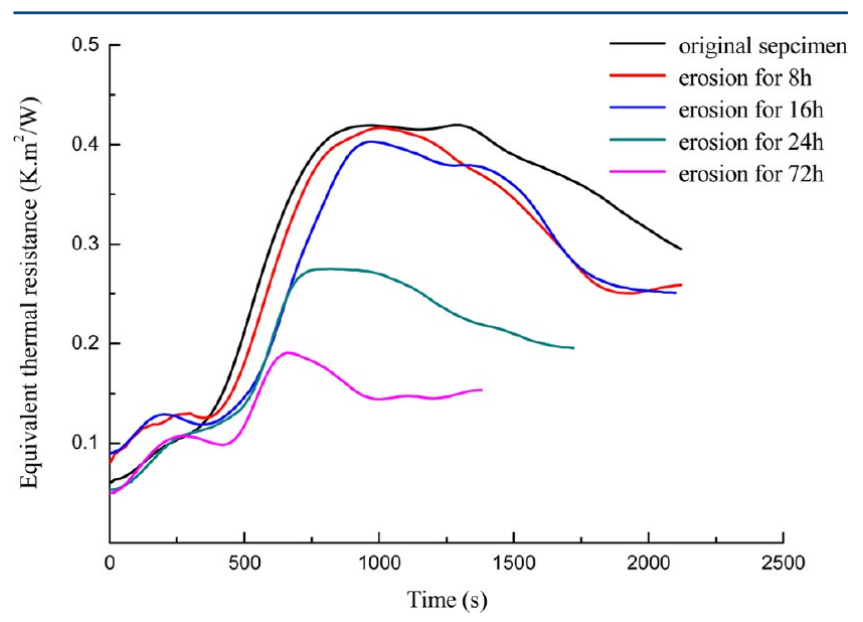

Figure 11. Equivalent thermal resistance vs time of the samples for different corrosion times.

samples for different corrosion times with the heating time. As shown in Figure 11, with the acid corrosion time extended, the equivalent thermal resistance of the coating exhibits an overall trend of decreasing. In the initial $400 \mathrm{~s}$, the equivalent thermal resistance of the 8 and $16 \mathrm{~h}$ corrosion samples is slightly higher than that of the others. During this test time period, the back temperature of the samples was below $200{ }^{\circ} \mathrm{C}$. The residual moisture in the coating may be the cause of the higher thermal resistance of the 8 and $16 \mathrm{~h}$ corrosion specimens. However, because the thermal resistance during this period is relatively small, and the duration is short, the effect of the thermal resistance difference for the back side temperature of the sample is not significant (see Figure 4). For the heating from $700 \mathrm{~s}$ to the end of the test, the equivalent thermal resistances of the samples of different corrosion times exhibit a remarkable 
Table 3. Pore Sizes of the Samples for the Different Corrosion Times

\begin{tabular}{|c|c|c|c|c|c|c|}
\hline $\begin{array}{l}\text { corrosion } \\
\text { time }(\mathrm{h})\end{array}$ & $\begin{array}{l}\text { the largest pore } \\
\text { size }(\mathrm{m})\end{array}$ & $\begin{array}{l}\text { the smallest pore } \\
\text { size }(\mu \mathrm{m})\end{array}$ & $\begin{array}{l}\text { the average pore size } \\
(\mu \mathrm{m})\end{array}$ & $\begin{array}{l}\text { the range of the pore } \\
\qquad(\mu \mathrm{m})\end{array}$ & $\begin{array}{l}\text { the variance of the pore } \\
\qquad\left(\mu \mathrm{m}^{2}\right)\end{array}$ & $\begin{array}{l}\text { the standard deviation of the } \\
\text { pore }(\mu \mathrm{m})\end{array}$ \\
\hline 0 & 277.87 & 61.50 & 125.18 & 216.37 & 2655.07 & 51.53 \\
\hline 8 & 569.67 & 79.81 & 202.09 & 489.86 & 15467.05 & 124.37 \\
\hline 16 & 645.69 & 131.74 & 344.79 & 513.95 & 32577.16 & 180.49 \\
\hline
\end{tabular}

difference. For example, the equivalent thermal resistances of the untreated sample and the $72 \mathrm{~h}$ corrosion sample are 0.364 and $0.189 \mathrm{~K} \cdot \mathrm{m}^{2} / \mathrm{W}$, respectively; i.e., the former is 1.93 times the latter. At $960 \mathrm{~s}$, the equivalent thermal resistances of the untreated sample and the $72 \mathrm{~h}$ corrosion sample are 0.419 and $0.146 \mathrm{~K} \cdot \mathrm{m}^{2} / \mathrm{W}$, respectively; the former is 2.87 times of the latter. Regarding the significant differences of the samples over a long time, the insulation effects of the different samples are remarkably diverse, and the resistance times of the samples are distinct from each other.

3.3. FTIR Test Results. FTIR test was used to investigate the variation of the groups contained in the coating surface components, analyze the possible chemical reactions during the acid corrosion, infer the mechanism of the acid corrosion aging of the coating, and determine the reason for the changes of the fire resistance performance. The experimental results are presented in Figure 12.

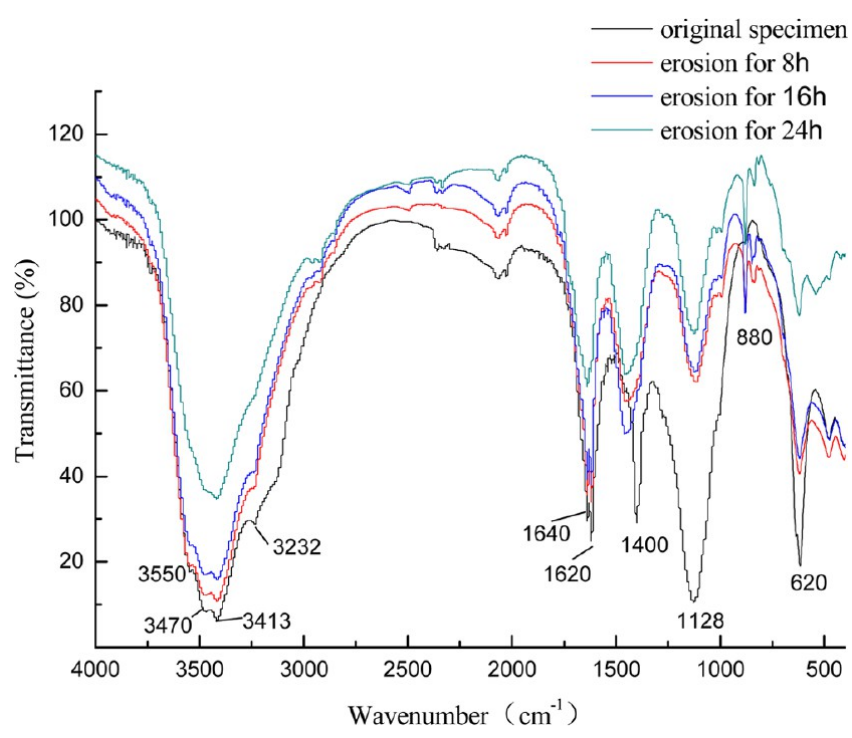

Figure 12. FTIR spectrum of the samples for different corrosion times.

As shown in Figure 12, the groups of the components contained in the different corrosion time samples are similar, but there are slight differences in the contents. The trough at $3550 \mathrm{~cm}^{-1}$ indicates the stretching vibration of the $\mathrm{O}-\mathrm{H}$ contained in PER; the troughs at 3470 and $3414 \mathrm{~cm}^{-1}$ indicate the stretching vibration of the $\mathrm{NH}_{2}$ contained in MEL; the trough at $3232 \mathrm{~cm}^{-1}$ also indicates the stretching vibration of the $\mathrm{O}-\mathrm{H}$; the trough at $1640 \mathrm{~cm}^{-1}$ indicates the stretching vibration of the $\mathrm{C}=\mathrm{O}$ contained in the base resin of the coating; the trough at $1620 \mathrm{~cm}^{-1}$ indicates the deformation vibration of the $\mathrm{NH}_{2}$; the trough at $1400 \mathrm{~cm}^{-1}$ indicates the twisting vibration of the $\mathrm{C}-\mathrm{H}$ bonds in $\mathrm{CH}_{2}$ contained in the base resin of the coating and PER; the trough at $1128 \mathrm{~cm}^{-1}$ indicates the stretching vibration of the $\mathrm{PO}_{4}$ and $\mathrm{C}-\mathrm{O}$ in the alcohol contained in APP and PER, respectively; the trough at $620 \mathrm{~cm}^{-1}$ indicates the out-of-plane bending vibration of the
$\mathrm{O}-\mathrm{H}$ bond; the trough at $885 \mathrm{~cm}^{-1}$ (not appearing in the original sample testing result) indicates the stretching vibration of the $\mathrm{P}-\mathrm{O}-\mathrm{P}$ in the pyrophosphate.

Analyzing the troughs in the figure, the troughs at 3550 and $3232 \mathrm{~cm}^{-1}$ are observed to weaken and eventually disappear with the corrosion time increasing. These results indicate that the PER particles contained in the coating were dissolved in the hydrochloric acid solution during the corrosion process and that the contents in the coating were decreasing. When the corrosion time is relatively short, because of the diffusion of the inertial PER to the surface, the reduction of the groups is not obvious. When the corrosion time reached $24 \mathrm{~h}$, these two troughs disappeared, which demonstrates that the content of the PER decreased significantly; in addition, the weakening of the troughs at wave numbers of 1128 and $620 \mathrm{~cm}^{-1}$ also proves this phenomenon. The troughs at 3470, 3414, and $1620 \mathrm{~cm}^{-1}$, which are related to MEL, have similar trends to those of PER. That is, for the short duration corrosion samples, the content of the MEL is slightly affected, but for the long duration corrosion samples, the MEL content significantly decreases. In addition, the ammelid, ammeline, and cyanuric acids produced in the action of MEL and hydrochloric acid exhibit absorption peaks at the wavenumbers of 3470,3414 , and $1620 \mathrm{~cm}^{-1}$, which also exhibit only slight changes of the troughs for the short time corrosion samples. Considering the troughs in the vicinity of $1400 \mathrm{~cm}^{-1}$, compared with the untreated coating, the troughs of the corrosion samples become weaker and shifted to the higher wavenumbers. The reason for this phenomenon is that the polarity of the $\mathrm{C}-\mathrm{H}$ contained in the PER, which is adjacent to the $\mathrm{OH}$, is stronger than the $\mathrm{C}-\mathrm{H}$ contained in the base resin. Thus, when the content of the PER decreased, the troughs not only become weak but also shift to the higher wavenumber for the reduced polarity of the $\mathrm{C}-\mathrm{H}$. The APP hydrolyzes in water, and the presence of the acid can accelerate this process. The troughs at $885 \mathrm{~cm}^{-1}$ appear in the corroded samples, indicating that the pyrophosphate was generated during the hydrolysis of APP. In addition, the content of the pyrophosphate increases with the prolonging of the corrosion time. At the same time, the weakening of the absorption peak at $1128 \mathrm{~cm}^{-1}$ also indicates the hydrolysis of the APP.

In summary, some coating components may have undergone acid catalyzed hydrolysis. The troughs indicate that the vibrations of $\mathrm{O}-\mathrm{H}, \mathrm{NH}_{2}$, and $\mathrm{PO}_{4}$ contained in PER, MEL, and APP are weakened. However, the trough corresponding to the pyrophosphate generated in the hydrolysis of the APP becomes stronger. Thus, according to the variation of the characterized troughs, the corrosion degree of the coating used in the real engineering can be roughly predicted.

3.4. XPS Test Results. XPS (X-ray photoelectron spectroscopy) provides information on the amount of chemical elements being examined. According to the main compositions in the sample coating, the element contents of $\mathrm{C}, \mathrm{N}, \mathrm{O}, \mathrm{P}$, and $\mathrm{Cl}$ were measured. The variation of the amounts of the elements can reflect the changes of the components in the 


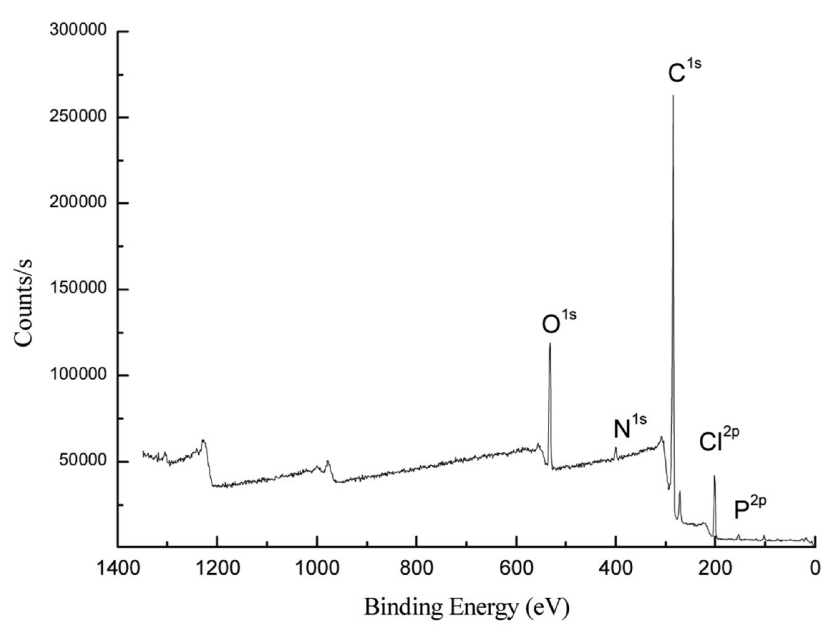

a. Original sample

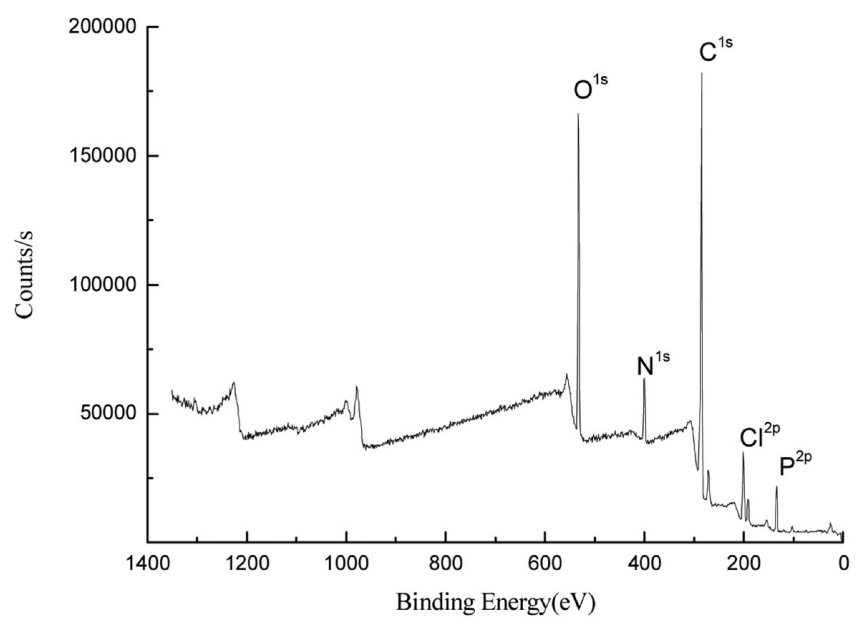

c. Corrosion for $24 \mathrm{~h}$

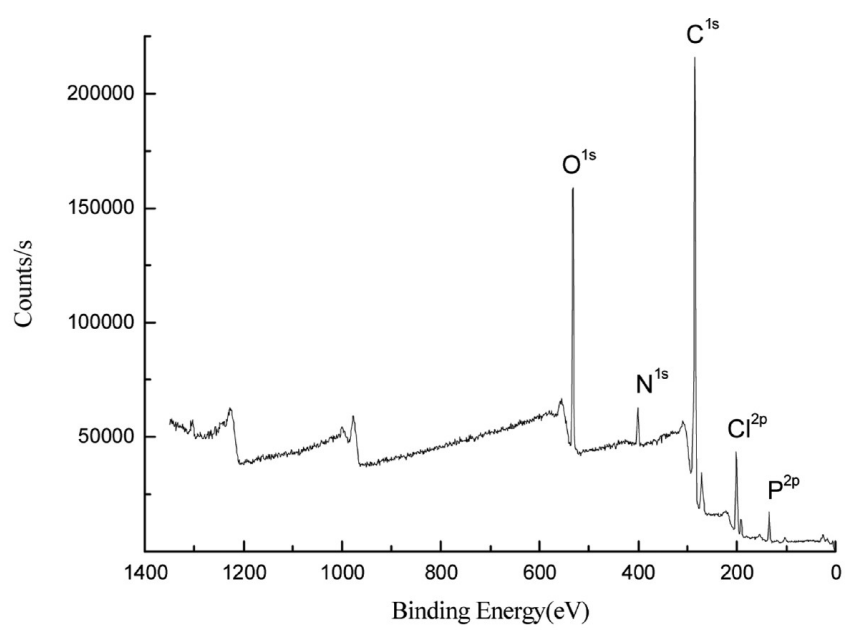

b. Corrosion for $8 \mathrm{~h}$

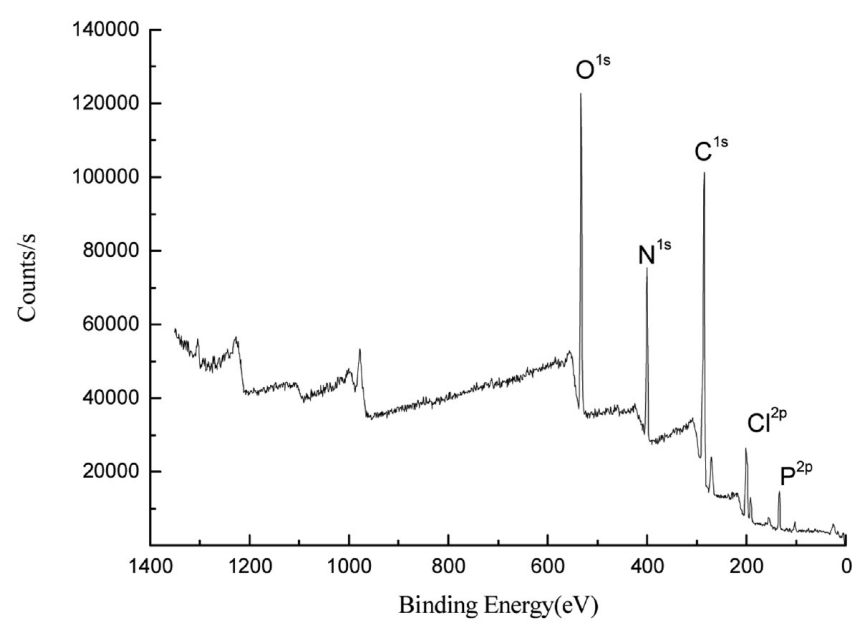

d. Corrosion for $72 \mathrm{~h}$

Figure 13. XPS test results of the samples for different corrosion times.

coating surface after different periods of acid corrosion. Figure 13 shows the XPS test results of the samples.

As listed in Table 4, with the corrosion time prolonged, the contents of the elements are increasing, except for the $\mathrm{C}$ element. Of all the components of the coating, those containing the $\mathrm{C}$ element are acrylic resin, MEL, PER, and chlorinated paraffin; those that contain the $\mathrm{O}$ element are acrylic resin, APP, PER, and titanium dioxide; the component containing the $\mathrm{Cl}$ element is chlorinated paraffin; those components that contain the $\mathrm{N}$ element are APP and MEL; the component that contains the $\mathrm{P}$ element is APP.

The $\mathrm{C}$ element is mainly contained in acrylic resin. During the corrosion in the hydrochloric acid solution, some watersoluble and hydrolyzable components diffused to the surface of the fire retardant coating and then were concentrated in the outermost layer above the base resin. Because only the surface elements were measured, the content of the $\mathrm{C}$ element decreased obviously. Although the reduction content of resin in the coating surface caused the decrease of the $\mathrm{O}$ element, the diffusion of the APP and PER to the surface caused an overall increase of the content of the $\mathrm{O}$ element. In the untreated coating, the $\mathrm{Cl}$ element was contained in the chlorinated
Table 4. Element Contents in the Samples for Different Times of Corrosion

\begin{tabular}{ccccc} 
& \multicolumn{4}{c}{ content (\%) } \\
\cline { 2 - 5 } element & $\begin{array}{c}\text { original } \\
\text { sample }\end{array}$ & $\begin{array}{c}\text { corrosion for } \\
8 \mathrm{~h}\end{array}$ & $\begin{array}{c}\text { corrosion for } \\
24 \mathrm{~h}\end{array}$ & $\begin{array}{c}\text { corrosion for } \\
72 \mathrm{~h}\end{array}$ \\
$\mathrm{C}$ & 79.45 & 64.24 & 59.4 & 48.07 \\
$\mathrm{O}$ & 10.53 & 16.75 & 19.45 & 18.58 \\
$\mathrm{Cl}$ & 5.82 & 10.63 & 9.45 & 14.21 \\
$\mathrm{~N}$ & 2.6 & 4.22 & 5.95 & 10.88 \\
$\mathrm{P}$ & 1.6 & 3.19 & 4.28 & 4.29 \\
\hline
\end{tabular}

paraffin. After the emission in the hydrochloric acid solution, there were small amount of hydrochloric acid and chlorine salt attached on the surface of the coating, which led to an increase in the content of $\mathrm{Cl}$ element. The increasing content of the $\mathrm{N}$ element in the short time corrosion process is caused by the diffusion of the APP and MEL to the coating surface, and in the long time corrosion, it is caused by the nitrogen contained in the small molecular products generated in the hydrolysis of APP and MEL. In the virgin coating sample, the P element was contained only in APP. The content variation of the P element 
can appropriately reflect the diffusion situation of APP. The surface characterization results, the fire resistance test results, and the FTIR test results in the samples for less than $24 \mathrm{~h}$ of corrosion indicate that there was still a certain amount of APP in the coating surface and the internal part. When the corrosion time exceeded $24 \mathrm{~h}$, a significant amount of APP was lost due to the acid catalyzed hydrolysis. The small molecular products, such as pyrophosphate, remained on the surface of the coating. Although the elements content was similar, the molecular structure of the pyrophosphate was completely different from that of APP, and this would result in an obvious difference in the fire resistance performance.

\section{THE PREDICTION OF THE REMAINING FIRE RESISTANCE PROPERTY OF THE COATINGS}

If the coating type and initial layer thickness were similar to the studied one in this paper, according to the thinning of the coating, the remaining fire resistance property of the coating for a certain time acid corrosion can be predicted roughly and directly by the data in Table 2 . However, in practical engineering, the fire retardant coating type and thickness are usually determined by the demand of the fire protecting design and are often different. In addition, in this research, the specimens were not completely soaked in the acid solution, which deviates from the actual situation. Thus, to obtain the fire resistance performance of the fire coating used in the acid corrosion environment over some years, the coating samples extracted from the substrate should be tested by examining the surface morphology, FTIR, and XPS, and the test results should be compared comprehensively with the case studied in this paper. The accelerated acid corrosion time can be determined under the laboratory conditions. The samples, with the same coating thickness as the pro-corrosion thickness of the engineering coating, should be completely immersed in the acid solution. The bench scale fire resistance test can be used to determine the remaining fire resistance time of the fire coating in the actual engineering practice.

Note that, in the testing process, the temperature-time curve in the test furnace should be calibrated according to the possible fire scenario in which the coating may encounter. For example, the fires that occur in the petrochemical enterprises correspond to hydrocarbon fires (UL 1709), and the fire in common buildings correspond to fiber fire (ISO 834).

\section{CONCLUSIONS}

During the process of acid corrosion, certain components of the intumenscent fire retardant coating are lost due to dissolution, acid catalyzed hydrolysis, and chemical reaction with the acid, resulting in the deterioration of the fire resistance property. When the coating surface and char layer morphology were examined after the acid corrosion, the thickness of the coating was found to be thinned and the surface was found to become rough and exhibit cracks and broken holes; the size of the pores in the char layer were larger and uneven, and some "cement" parts were formed.

Regarding the equivalent thermal resistance of the tested samples, during the initial $400 \mathrm{~s}$, the equivalent thermal resistance of the samples for 8 and $16 \mathrm{~h}$ of corrosion was slightly higher than that of the others due to the residual moisture in the coating. While in the later part of the heating, the equivalent thermal resistances of the samples with different corrosion times exhibited a remarkable difference, which led to the remarkably diverse insulation effects and the distinct resistance time.

When immersed in the acid solution, the APP, PER, and MEL would undergo the process of acid catalyzed hydrolysis, dissolution, and chemical reaction. Thus, as the FTIR tests results reflected, the troughs indicating the vibrations of $\mathrm{O}-\mathrm{H}$, $\mathrm{NH}_{2}$, and $\mathrm{PO}_{4}$ contained in PER, MEL, and APP were weakened gradually, while the trough that corresponded to the pyrophosphate produced in the hydrolysis of APP was strengthened.

The contents of the elements $\mathrm{C}, \mathrm{N}, \mathrm{O}, \mathrm{P}$, and $\mathrm{Cl}$ were measured using the method of XPS. According to the XPS results, with the corrosion time prolonged, the contents of the elements were increasing, except for the $\mathrm{C}$ element, which indicated the diffusion and loss of PER, MEL, and APP.

A prediction method of the remained fire resistance property for the acid corrosion coatings was proposed that comprehensively considers the changing trends of the physical and chemical characteristics of the corroded coating. This method can be a reference for the fire safety evaluation of built protected steel structures.

The aging mechanism and the variation of the fire resistance performance were studied only in the acid corrosion condition. In practical engineering, the fire retardant coatings for outdoor use are affected by a variety of climatic factors, such as temperature, radiation, oxidation, etc. All of these factors will cause the physical, chemical, and fire resistance properties to become worse.

It should be pointed out that the samples investigated in this study were without top coating, but in practice, intumescent coatings may be top coated to protect them from environmental damage. Their durability will be much better.

\section{AUTHOR INFORMATION}

\section{Corresponding Author}

*E-mail: 10115094@qq.com. Tel: 0086-13752457108.

\section{Notes}

The authors declare no competing financial interest.

\section{ACKNOWLEDGMENTS}

The authors would like to thank Professor Min Zhao and Doctor Jun-li Sun for their help in the analysis of the experimental results and the corrosion mechanism.

\section{REFERENCES}

(1) Norvaišienè, R.; Burlingis, A.; Stankevičius, V. Durability tests on painted facade rendering by accelerated ageing. Mater. Sci. 2010, 16, $80-85$.

(2) Deflorian, F.; Rossi, S.; Fedrizzi, L.; Zanella, C. Comparison of organic coating accelerated tests and natural weathering considering meteorological data. Prog. Org. Coat. 2007, 59, 244-250.

(3) Schulz, U.; Trubiroha, P.; Schernau, U.; et al. The effects of acid rain on the appearance of automotive paint systems studied outdoors and in a new artificial weathering test. Prog. Org. Coat. 2000, 40, 151165 .

(4) Guseva, O.; Brunner, S.; Richner, P. Service life prediction for aircraft coatings. Polym. Degrad. Stab. 2003, 82, 1-13.

(5) Shi, X. D.; Dilhan Fernando, B. M.; Croll, S. G. Concurrent physical aging and degradation of crosslinked coating systems in accelerated weathering. J. Coat. Technol. Res. 2008, 5, 299-309.

(6) Hua, J. W.; Li, X. G.; Gao, J.; Zhao, Q. L. UV aging characterization of epoxy varnish coated steel upon exposure to artificial weathering environment. Mater. Des. 2009, 30, 1542-1547. 
(7) Sakumoto, B. Y.; Nagata, J.; Kodaira, A.; Saito, Y. Durability evaluation of intumescent coating for steel frames. J. Mater. Civil Eng. 2001, 13, 274-281.

(8) Roberts, T. A.; Shirvill, L. C.; Waterton, K.; Buckland, I. Fire resistance of passive fire protection coatings after long-term weathering. Process Saf. Environ. Prot. 2010, 88, 1-19.

(9) Wang, L. L.; Wang, Y. C.; Li, G. Q. Experimental study of hydrothermal aging effects on insulative properties of intumescent coating for steel elements. Fire Saf. J. 2013, 55, 168-181.

(10) Jimenez, M.; Bellayer, S.; Revel, B.; et al. Comprehensive study of the influence of different aging scenarios on the fire protective hehavior of an epoxy based intumescent coating. Ind. Eng. Chem. Res. 2013, 52, 929-743.

(11) Rodgers, W. R.; Garner, G. D.; Cheever, G. D. Study of the acid resistance of melamine-acrylic basecoat/clear coat paint systems. Eur. Coat. J. 1998, 7, 70.

(12) Wolff, G. T.; Rodgers, W. R.; Collins, D. C.; Verma, M. H.; Wong, C. A. Spotting of automotive finishes from the interactions between dry deposition of crustal material and wet deposition of sulfate. J. Air Waste Manage. Assoc. 1990, 40, 1638-1648.

(13) Underwriters Laboratories Inc. UL1709-2005: UL Standard for Safety for Rapid Rise Fire Tests of Protection Materials for Structural Steel; National Fire Protection Association: Northbrook, IL, 2005.

(14) Beijing Institute of Aerial Materials of China Aviation Industry Corporation. Testing electric furnace and testing method for intumescent coatings. Chinese Patent 200610167761.1, 2007.

(15) Luo, J. Y.; Lu, X. M.; Sun, C. Y. Ammonium Polyphosphate and Its Application; Chemical Industry Press: Beijing, 2006.

(16) European Commission for Constructional Steelwork. Design manual on the european recommendation for the fire safety of steel structures; ECCS: Brussels, 1985.

(17) Kantorovich, I. I.; Bar-Ziv, E. Heat transfer within highly porous chars: A review. Fuel 1999, 78, 279-299.

(18) Staggs, J. E. J. Thermal conductivity estimates of intumescent chars by direct numerical simulation. Fire Saf. J. 2010, 45, 238-247.

(19) Staggs, J. E. J.; Crewe, R. J.; Butler, R. A theoretical and experimental investigation of intumescent behaviour in protective coatings for structural steel. Chem. Eng. Sci. 2012, 71, 239-251.

(20) Carson, J. K.; Lovatt, S. J.; Tanner, D. J. Thermal conductivity bounds for isotropic, porous materials. Int. J. Heat Mass Transfer 2005, 48, 2150-2158.

(21) Bartholmai, M.; Schriever, R. Influence of external heat flux and coating thickness on the thermal insulation properties of two different intumescent coatings using cone calorimeter and numerical analysis. Fire Mater. 2003, 37, 151-162.

(22) Li, G. Q.; Lou, G. B.; Zhang, C. Assess the fire resistance of intumescent coatings by equivalent constant thermal resistance. Fire Technol. 2012, 48, 529-546.

(23) Li, G. Q.; Han, H. L.; Lou, G. B. Fire resistance design of the steel structure and the steel-concrete combined structure; Chinese Building Industry Press: Beijing, 2006.

(24) MacCallum, J. R; Tanner, J. Electroencephalography and clinical neurophysiology. Eur. Polym. J. 1968, 4, 333.

(25) Shen, C. Y. Preparation and characterization of crystalline longchain ammonium polyphosphates. J. Am. Chem. Soc. 1969, 91, 62-67. 